Case report

\title{
Carcinomatous meningitis in a patient with Her2/neu expressing bladder cancer following trastuzumab and chemotherapy: a case report and review of the literature
}

\author{
Oscar B Goodman $\mathrm{Jr}^{1}$, Matthew I Milowsky², Jodi Kaplan², Maha Hussain ${ }^{3}$ \\ and David M Nanus ${ }^{2 *}$
}

\author{
Addresses: ${ }^{1}$ Division of Clinical Oncology, Nevada Cancer Institute, Las Vegas, NV 89135, USA \\ ${ }^{2}$ Division of Hematology and Medical Oncology, Department of Medicine, Weill Medical College of Cornell University - New York Presbyterian \\ Hospital, New York, NY 10021, USA \\ ${ }^{3}$ Division of Hematology and Medical Oncology, Department of Medicine, University of Michigan, Ann Arbor, MI 48109, USA \\ Email: DMN* - dnanus@med.cornell.edu \\ * Corresponding author
}

Received: 18 August 2008 Accepted: 8 April 2009 Published: 15 September 2009

Journal of Medical Case Reports 2009, 3:9110 doi: 10.4076/1752-1947-3-91 I0

This article is available from: http://jmedicalcasereports.com/jmedicalcasereports/article/view/91/0

(C) 2009 Goodman Jr et al.; licensee Cases Network Ltd.

This is an Open Access article distributed under the terms of the Creative Commons Attribution License (http://creativecommons.org/licenses/by/3.0), which permits unrestricted use, distribution, and reproduction in any medium, provided the original work is properly cited.

\begin{abstract}
Introduction: Targeted therapies may impact the natural history of bladder cancer based upon their pharmacokinetics. The Her2/neu receptor tyrosine kinase, overexpressed by half of all primary urothelial carcinomas, has recently been examined as a therapeutic target in bladder cancer in a prospective phase II multicenter trial ( $\mathrm{NCl}$-198) that enrolled 109 patients with advanced bladder carcinomas for treatment with trastuzumab in combination with paclitaxel, carboplatin, and gemcitabine. We report on documented isolated Her2/neu positive carcinomatous meningitis in a patient treated with trastuzumab.

Case presentation: A 6I-year-old Caucasian man with metastatic bladder cancer was treated with neoadjuvant chemotherapy in combination with trastuzumab with a partial response that was followed by a complete response after surgery. He relapsed with isolated Her $2 /$ neu positive carcinomatous meningitis.

Conclusion: Carcinomatous meningitis in bladder cancer is extremely rare. This is the first case reported of Her2/neu positive carcinomatous meningitis. Disease recurred solely at a sanctuary site, demonstrating that despite the systemic efficacy of trastuzumab in combination with chemotherapy, its inability to enter the central nervous system potentially contributes to the unusual site of disease recurrence.
\end{abstract}

\section{Introduction}

The Her2/neu receptor tyrosine kinase is overexpressed by the majority of all primary invasive urothelial carcinomas [1]. The epidermal growth factor receptor (EGFR) tyrosine kinase family comprises four members (erbB-1 through
erbB-4), with erbB-1 (EGFR) and erbB-2 (Her2/neu) expressed in urothelial carcinoma [2]. Following ligand activation, the receptors dimerize resulting in stimulation of multiple signaling pathways, leading to increased cell growth and survival [3]. Her2/neu-mediated signaling 
activates important oncogenic signaling cascades such as the ras-mitogen activated protein (MAP)-kinase pathway, phospholipase C-gamma (PLC- $\gamma$ ) and phosphatidylinositol-3 (PI-3) kinase [4]. Overexpression of Her2/neu is associated with higher tumor grade and decreased diseaserelated survival [5], suggesting a specific role for Her2/neu in bladder cancer progression. Gene amplification is rarely observed, in contrast to breast cancer where gene amplification is seen in about $25 \%$ of cases and correlates with Her2/neu protein overexpression [6]. Although the mechanism for gene overexpression is not well understood, most evidence points to a transcriptional mechanism mediated by the transcription factor OB2-1 [7]. We report the case of a patient who had a complete response to surgery but relapsed with isolated Her2/neu positive carcinomatous meningitis. Advances in multimodality therapies including neoadjuvant chemotherapy in bladder cancer may alter the natural history of this disease.

This case represents the first report of Her2/neu positive urothelial carcinomatous meningitis. Several recent studies have implicated Her2/neu overexpression in the progression of urothelial carcinoma. Overexpression of Her2/neu is associated with higher tumor grade and decreased diseaserelated survival [5]. A cohort study of 245 patients revealed that $45 \%$ of the tumors expressed Her2/neu protein and expression correlated with higher grade, tumor recurrence, and decreased survival, especially when co-expressed with ErbB1 or ErbB3 [8]. In a series of 80 consecutive cases of muscle-invasive urothelial bladder carcinomas, Jimenez and colleagues showed that $45 \%$ of Her2/neu negative primary disease had Her2/neu positive metastatic nodal disease, while only one case (8\%) of Her2/neu positive primary disease manifested with Her-2/neu negative nodal metastatic disease [9]. Collectively, these data indicate that Her2/neu expression may be predictive of tumor aggressiveness and contribute to metastasis.

The phase II NCI-198 (NCT00005831) trial prospectively evaluated the safety and efficacy of open label trastuzumab in combination with chemotherapy in patients with documented Her2/neu positive advanced urothelial carcinoma. Eligible patients received paclitaxel $\left(200 \mathrm{mg} / \mathrm{m}^{2}\right.$ day 1 ), carboplatin (AUC 5 day 1), gemcitabine $(800 \mathrm{mg} /$ $\mathrm{m}^{2}$ days 1,8$)$ and trastuzumab $(4 \mathrm{mg} / \mathrm{kg}$ loading dose, then $2 \mathrm{mg} / \mathrm{kg}$ days $1,8,15)$ every 21 days. Of 109 patients screened for the study, 57 (52\%) were Her2/neu positive and of these, 44 were eligible for protocol therapy. Her2/ neu positive patients had a greater mean number of metastatic sites ( 2 versus $1, p=0.014$ ). The overall response rate was $31 / 44(70 \%)$, with a median time to progression of 9.3 months and a median survival of 14.1 months [10]. These findings compared favorably with historical controls, for example, gemcitabine/cisplatin-treated patients had an overall response rate of $49 \%$, a median progression-free survival of 7.7 months and a median survival of 14.0 months $[11,12]$. Notably, however, nearly one-third of these patients had tumors that were not metastatic, possibly explaining the similar median survival between the two groups [10].

\section{Case presentation}

A 61-year-old Caucasian man with a history of benzidine exposure and tobacco use presented with intermittent gross hematuria over the previous 2 months. Cystoscopy and transurethral resection of the bladder revealed a $2 \mathrm{~cm}$ high grade muscle invasive urothelial carcinoma. A staging computed tomography (CT) scan identified extensive retroperitoneal lymphadenopathy with a conglomerate of nodes at the aortic bifurcation measuring $7.6 \times 3.5 \mathrm{~cm}$ and with the largest individual node found at the level of the right common iliac bifurcation measuring $2.7 \times 3.9 \mathrm{~cm}$. Biopsy of this lymph node confirmed metastatic urothelial carcinoma. Immunohistochemical analysis of the primary tumor revealed 3+ Her2/neu positivity, while fluorescence in situ hybridization (FISH) analysis revealed no Her2/neu gene amplification. The patient was enrolled on the NCI198 trial with paclitaxel $\left(200 \mathrm{mg} / \mathrm{m}^{2}\right.$ day 1$)$, carboplatin (AUC 5 day 1), gemcitabine $\left(800 \mathrm{mg} / \mathrm{m}^{2}\right.$ days 1,8$)$ and trastuzumab $(4 \mathrm{mg} / \mathrm{kg}$ loading dose, then $2 \mathrm{mg} / \mathrm{kg}$ days $1,8,15)$ every 21 days. After six cycles, a CT scan demonstrated a partial response in the retroperitoneum, with the right common iliac node measuring $1.2 \times 0.8 \mathrm{~cm}$, corresponding to a $>95 \%$ decrease in volume [13]. He then underwent a radical cystectomy and extensive lymph node dissection with removal of 69 nodes, revealing pT2aNOM0 high grade disease and resulting in a surgically rendered complete response.

Two weeks postoperatively, the patient developed paresthesia and proprioceptive deficits in his hands and feet that were attributed to nerve compression that occurred during prolonged surgery. Nerve conduction studies revealed an axonal sensorimotor polyradicular neuropathy with demyelinating features. Neurologic symptoms did not improve with gabapentin therapy and a lumbar puncture five months postoperatively revealed carcinoma cells. Immunohistochemical analysis of the cerebrospinal fluid (CSF) revealed 2+ Her2/neu expression (Figure 1). Magnetic resonance imaging (MRI) of the brain confirmed diffuse leptomeningeal enhancement along with cerebellar metastases (Figure 2). A CT scan of the chest, abdomen and pelvis revealed no evidence of systemic recurrence. An Ommaya reservoir was placed and the patient received four weeks of biweekly intrathecal methotrexate therapy, resulting in negative repeat cytologic CSF evaluations after two weeks of therapy. After week four, intrathecal therapy was stopped due to urosepsis, and a repeat cytologic evaluation one week later revealed recurrent carcinomatous meningitis. The 


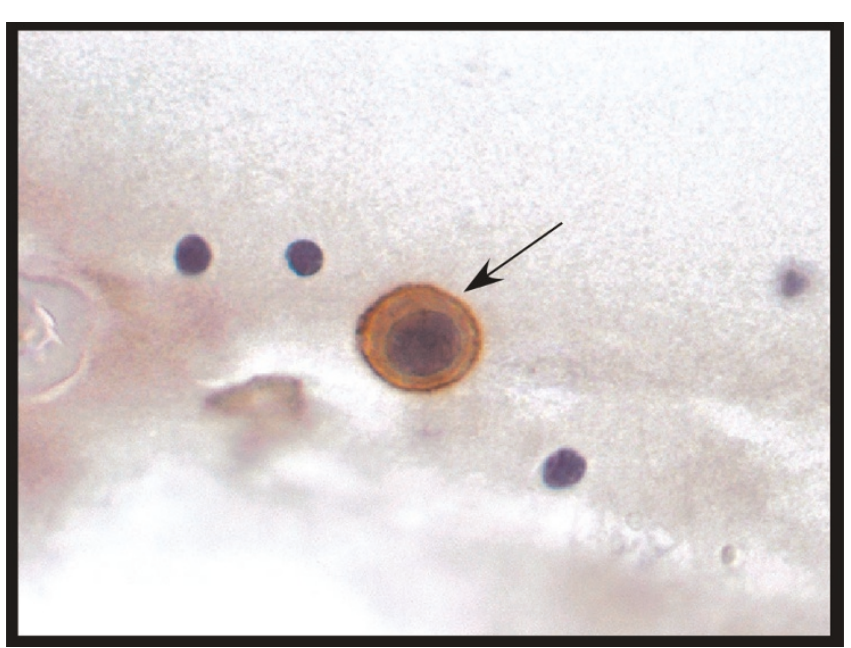

Figure I. Immunohistochemical staining of cerebrospinal fluid revealing a 2+ Her2/neu positive malignant cell (arrow).

patient refused further chemotherapy and died two weeks later.

\section{Discussion}

Following treatment, our patient relapsed with isolated Her2/neu positive carcinomatous meningitis. Carcinomatous meningitis is rare in bladder cancer [14-16]. Trastuzumab does not cross the blood-brain barrier [17], suggesting that targeting Her2/neu positive systemic disease may alter the natural history of bladder carcinoma metastasis predisposing to the onset and progression of

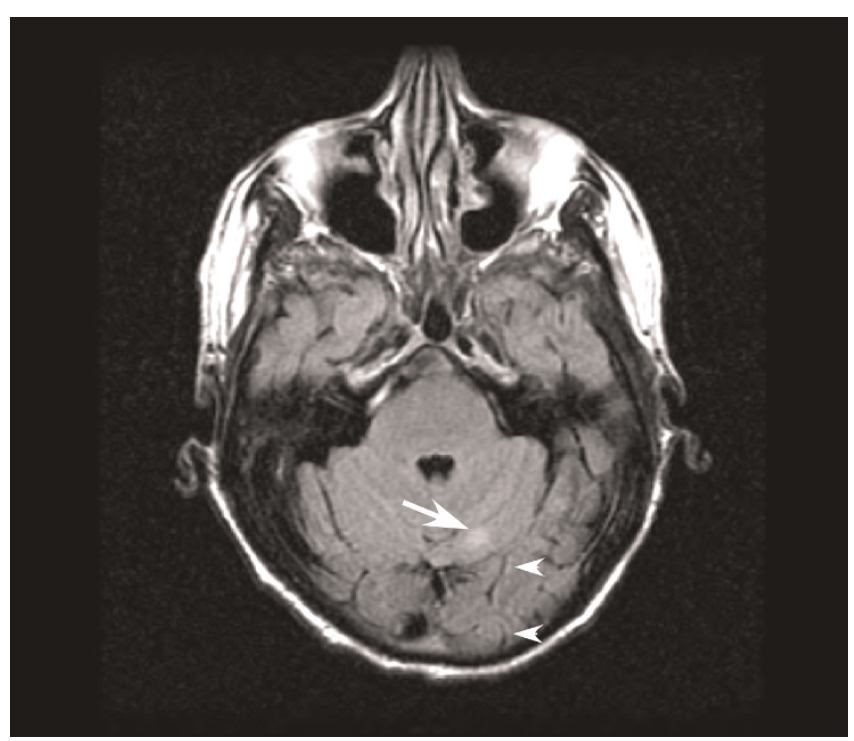

Figure 2. TI-weighted brain magnetic resonance imaging demonstrating both leptomeningeal enhancement (arrowheads) and a cerebellar metastasis (arrow). central nervous system (CNS) disease. Her2/neu expression in breast cancer CNS metastases is highly concordant with systemic disease status, with $93 \%$ of patients with Her2/neu positive primary tumors also expressing Her2/ neu in CNS metastatic disease [18]. Given similar concordance in bladder cancer [9] as well as the fact that Her2/neu expression is more common in bladder cancer than in breast cancer [5], it remains to be seen if the incidence of carcinomatous meningitis due to leptomeningeal bladder metastases will increase in the setting of trastuzumab therapy as a consequence of systemic therapeutic efficacy and poor CNS bioavailability.

Despite the presence of Her2/neu positive disease, it is possible that the initial clinical response and subsequent CNS relapse in our patient was not due to trastuzumab but to carboplatin, gemcitabine and paclitaxel. Of the chemotherapeutic drugs, carboplatin has the highest CNS penetration with a peak CSF/plasma ratio of $28 \%$ but with significant interpatient variability (range 17-46\%) [19], while gemcitabine and paclitaxel have markedly lower CNS penetration, with CSF:plasma ratios of $6.7 \%$ [20] and less than $1.8 \%$ (the limit of detection) [21], respectively. Thus, it is likely that the combination of paclitaxel, carboplatin and gemcitabine (TCG) has little if any therapeutic efficacy for CNS disease, while TCG in combination with trastuzumab may augment the systemic disease response, thereby predisposing to CNS relapse.

\section{Conclusions}

Carcinomatous meningitis is exceedingly rare in bladder cancer, with only a few cases reported. Trastuzumab may alter the natural history of bladder carcinoma metastasis predisposing to CNS relapse. This likely reflects the potential efficacy of the therapy as well as an inability of chemobiologic therapy to penetrate the CNS. As a consequence of its systemic therapeutic efficacy and poor CNS bioavailability, trastuzumab may alter the natural history of bladder carcinoma resulting in an unusual presentation of metastatic disease.

\section{Abbreviations}

CNS, central nervous system; CSF, cerebrospinal fluid; EGFR, epidermal growth factor receptor; FISH, fluorescence in situ hybridization; MAP, mitogen activated protein; MRI, magnetic resonance imaging; NCI, National Cancer Institute; PI-3, phosphatidylinositol-3; PLC- $\gamma$, phospholipase C-gamma; TCG, paclitaxel, carboplatin and gemcitabine.

\section{Consent}

Written informed consent was obtained from the patient for publication of this case report and any accompanying 
images. A copy of the written consent is available for review by the Editor-in-Chief of this journal.

\section{Competing interests}

The authors declare that they have no competing interests.

\section{Authors' contributions}

OG assisted in the acquisition and analysis of the data, and in drafting the manuscript. $\mathrm{MM}$ analyzed the data and assisted in drafting the manuscript. JK assisted in the acquisition and analysis of the data. $\mathrm{MH}$ aided in the conception and design of this study, and in the acquisition and analysis of the data. DN assisted in the acquisition and analysis of the data, as well as drafting the manuscript. All authors have read and approved the final manuscript.

\section{Acknowledgements}

The authors acknowledge John Crapanzano, M.D. for his assistance in data acquisition. We acknowledge the patient and his family for his courageous participation on a clinical trial and fight against cancer. This work was supported by the Cancer Therapy Evaluation Program (CTEP), Cancer Center Core Grant 5P30CA046592-17, the John \& Suzanne Munn Endowed Research Fund, and Genentech.

\section{References}

I. Latif Z, Watters AD, Dunn I, Grigor K, Underwood MA, Bartlett JM: HER2/neu gene amplification and protein overexpression in G3 pT2 transitional cell carcinoma of the bladder: a role for anti-HER2 therapy? Eur J Cancer 2004, 40:56-63.

2. Rajjayabun PH, Keegan PE, Lunec L, Mellon JK: erbB receptor expression patterns in human bladder cancer. Urology 2005, 66:196-200

3. Sebastian S, Settleman J, Reshkin SJ, Azzariti A, Bellizzi A, Paradiso A: The complexity of targeting EGFR signalling in cancer: From expression to turnover. Biochim Biophys Acta 2006, 1766:120-139.

4. Reese DM, Slamon DJ: HER-2/neu signal transduction in human breast and ovarian cancer. Stem Cells 1997, I5:I-8.

5. Kruger S, Weitsch G, Buttner H, Matthiensen A, Bohmer T, Marquardt T, Sayk F, Feller AC, Bohle A: HER2 overexpression in muscle-invasive urothelial carcinoma of the bladder: prognostic implications. Int J Cancer 2002, 102:5|4-5|8.

6. Coogan CL, Estrada CR, Kapur S, Bloom KJ: HER-2/neu protein overexpression and gene amplification in human transitional cell carcinoma of the bladder. Urology 2004, 63:786-790.

7. Hollywood DP, Hurst HC: Targeting gene transcription: a new strategy to down-regulate c-erbB-2 expression in mammary carcinoma. Br J Cancer 1995, 7I:753-757.

8. Chow NH, Chan SH, Tzai TS, Ho CL, Liu HS: Expression profiles of ErbB family receptors and prognosis in primary transitional cell carcinoma of the urinary bladder. Clin Cancer Res 200I, 7:1957-1962.

9. Jimenez RE, Hussain M, Bianco FJ Jr, Vaishampayan U, Tabazcka P, Sakr WA, Pontes JE, Wood DP Jr, Grignon DJ: Her-2/neu overexpression in muscle-invasive urothelial carcinoma of the bladder: prognostic significance and comparative analysis in primary and metastatic tumors. Clin Cancer Res 200I, 7:24402447.

10. Hussain M, MacVicar GR, Petrylak D, Dunn R, Vaishampayan U, Lara PN, Chatta G, Nanus DM, Glode LM, Trump D, Chen H, Smith DC; National Cancer Institute: Trastuzumab, paclitaxel, carboplatin, and gemcitabine in advanced Her2/neu positive urothelial carcinoma: Results of a multi-center phase II NCI trial. J Clin Oncol 2007, 25:2218-2224.
II. von der Maase H, Hansen SW, Roberts JT, Dogliotti L, Oliver T, Moore MJ, Bodrogi I, Albers P, Knuth A, Lippert CM, Kerbrat P, Sanchez Rovira P, Wersall P, Cleall SP, Roychowdhury DF, Tomlin I, Visseren-Grul CM, Conte PF: Gemcitabine and cisplatin versus methotrexate, vinblastine, doxorubicin, and cisplatin in advanced or metastatic bladder cancer: results of a large, randomized, multinational, multicenter, phase III study. J Clin Oncol 2000, 18:3068-3077.

12. von der Maase H, Sengelov L, Roberts JT, Ricci S, Dogliotti L, Oliver T, Moore MJ, Zimmermann A, Arning M: Long-term survival results of a randomized trial comparing gemcitabine plus cisplatin, with methotrexate, vinblastine, doxorubicin, plus cisplatin in patients with bladder cancer. J Clin Oncol 2005, 23:4602-4608.

13. Therasse P, Arbuck SG, Eisenhauer EA, Wanders J, Kaplan RS, Rubinstein L, Verweij J, Van Glabbeke M, van Oosterom AT, Christian MC, Gwyther SG: New guidelines to evaluate the response to treatment in solid tumors European Organization for Research and Treatment of Cancer, National Cancer Institute of the United States, National Cancer Institute of Canada. J Natl Cancer Inst 2000, 92:205-216.

14. Eng C, Cunningham D, Quade BJ, Schwamm L, Kantoff PW Skarin AT: Meningeal carcinomatosis from transitional cell carcinoma of the bladder. Cancer 1993, 72:553-557.

15. Hara Y, Kobayashi Y, Goto K, Tozuka K, Tokue A, Mochizuki M: [A case of carcinomatous meningitis from transitional cell carcinoma of the urinary bladder]. Hinyokika Kiyo 1994, 40:III3-III7.

16. Matsushita M, Kawasaki Y, Okada Y: [Carcinomatous meningitis from urothelial carcinoma of bladder and ureter: case report]. Nippon Hinyokika Gakkai Zasshi 2004, 95:8I7-8I9.

17. Pestalozzi BC, Brignoli S: Trastuzumab in CSF. J Clin Oncol 2000, I 8:2349-235।.

18. Fuchs IB, Loebbecke M, Buhler H, Stoltenburg-Didinger G, Heine B, Lichtenegger W, Schaller G: HER2 in brain metastases: issues of concordance, survival, and treatment. I Clin Oncol 2002, 20:4I30-4I33.

19. Riccardi R, Riccardi A, Di Rocco C, Carelli G, Tartaglia RL, Lasorella A, Servidei T, Mastrangelo R: Cerebrospinal fluid pharmacokinetics of carboplatin in children with brain tumors. Cancer Chemother Pharmacol 1992, 30:21-24.

20. Kerr JZ, Berg SL, Dauser R, Nuchtern J, Egorin MJ, McGuffey L, Aleksic A, Blaney S: Plasma and cerebrospinal fluid pharmacokinetics of gemcitabine after intravenous administration in nonhuman primates. Cancer Chemother Pharmacol 200 I, 47:4 I I-4 I 4 .

21. Rowinsky EK, Burke PJ, Karp JE, Tucker RW, Ettinger DS, Donehower RC: Phase I and pharmacodynamic study of taxol in refractory acute leukemias. Cancer Res 1989, 49:4640-4647.

\section{Do you have a case to share?}

\author{
Submit your case report today \\ - Rapid peer review \\ - Fast publication \\ - PubMed indexing \\ - Inclusion in Cases Database
}

\section{Any patient, any case, can teach us something}

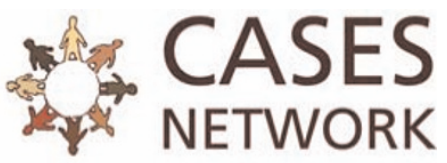

www.casesnetwork.com 